\title{
Organizational Justice and Health: Studying Mental Preoccupation With Work and Social Support as Mediators for Lagged and Reversed Relationships
}

AQ: au

AQ: 1

\author{
Constanze Eib \\ University of East Anglia and Stockholm University
}

\author{
Claudia Bernhard-Oettel, \\ Linda L. Magnusson Hanson, and \\ Constanze Leineweber \\ Stockholm University
}

\begin{abstract}
Organizational justice perceptions are considered a predictor of health and well-being. To date, empirical evidence about whether organizational justice perceptions predict health or health predicts organizational justice perceptions is mixed. Furthermore, the processes underlying these relationships are largely unknown. In this article, we study whether bidirectional relationships can be explained by 2 different mediation mechanisms. First, based on the allostatic load model, we suggest that the relationships between organizational justice perceptions and different health indicators are mediated through mental preoccupation with work. Second, based on the affective perception and affective reaction assumption, we investigate if the relationships between different health indicators and organizational justice perceptions are mediated by social support at work. Using a large-scale Swedish panel study $(N=3,236)$, we test the bidirectional mediating relationships between procedural justice perceptions and self-rated health, depressive symptoms, and sickness absence with a cross-lagged design with 3 waves of data. Significant lagged effects from procedural justice to health were found for models predicting depressive symptoms and sickness absence. Mental preoccupation with work was not found to mediate the longitudinal relationship between procedural justice perceptions and indicators of health. Significant lagged effects from health indicators to procedural justice were found for models involving self-rated health, depressive symptoms, and sickness absence. Social support mediated the longitudinal relationships between all 3 health indicators and procedural justice. Results are discussed in light of previous studies and implications for theory and practice are outlined.

Keywords: organizational justice, procedural justice, health, mental preoccupation, social support
\end{abstract}

\begin{abstract}
But perhaps the greatest strength of justice research is in its potential for improving the effectiveness of work organizations while simultaneously improving the lives of employees (Cropanzano \& Ambrose, 2015, p. 13)
\end{abstract}

Organizational justice is an important topic for employees and can be defined as an individual's perception of fairness at the workplace (Cropanzano, Byrne, Bobocel, \& Rupp, 2001). In a large number of studies, organizational justice perceptions have been related to work-related attitudes and behaviors such as performance, withdrawal, commitment, and job satisfaction (Colquitt, Conlon, Wesson, Porter, \& Ng, 2001; Colquitt et al., 2013; Rupp, Shao, Jones, \& Liao, 2014). In recent years, organizational justice, as an aspect of the work environment, has been scrutinized in its influence on individuals' well-being and health and found to relate to outcomes such as affect, health problems, or sickness absence (Ndjaboué, Brisson, \& Vézina, 2012; Robbins, Ford, \& Tetrick, 2012). Few studies have investigated how the justice-health relationship unfolds over time, and most of these are prospective studies including two time points only (Elovainio et al., 2015; Elovainio et al., 2013; Kivimäki, Elovainio, Vahtera, \& Ferrie, 2003). It has also been acknowledged that well-being and health may affect perceptions of the work environment. In other words, there is a possibility that reversed relationships also exist (Kawachi, 2006). However, findings have been contradictory, in particular when it comes to the existence of an effect from health to organizational justice. For instance, in a study based on a military
Constanze Eib, Norwich Business School, University of East Anglia, and Stress Research Institute, Stockholm University; Claudia BernhardOettel, Department of Psychology and Stockholm Stress Center, Stockholm University; Linda L. Magnusson Hanson and Constanze Leineweber, Stress Research Institute, Stockholm University.

A previous version of this study has been presented at the European Association of Work and Organizational Psychology (EAWOP) small group meeting "Studying work as it is: Capturing dynamics in workplace relationships" in Brussels in September 2015. This study was supported by the Swedish Foundation for Humanities and Social Science (RJ, Grant
P13-0905:1). The SLOSH study was supported by the Swedish Council for Working Life and Social Research (FAS, grant no. 2005-0734) and the Swedish Research Council (VR, grants no. 2009-6192 and 2013-1645). The work was carried out within the framework of the Stockholm Stress Center, a FORTE Centre of Excellence (FORTE, grant no. 2009-1758). The funding sources were neither involved in the conduct of the research nor in the preparation of the article.

Correspondence concerning this article should be addressed to Constanze Eib, Department of Psychology, Uppsala University, Blåsenhus von Kraemers allé 1E, 75237 Uppsala, Sweden. E-mail: constanze.eib @ gmail.com 
sample with two time points (Lang, Bliese, Lang, \& Adler, 2011), an effect from health to organizational justice was found, whereas other studies found mixed results (Ybema \& van den Bos, 2010), and yet others found only relationships from justice perceptions to health indicators (Elovainio et al., 2015). Hence, there is a need for more longitudinal studies with representative samples and repeated measurements of both justice perceptions and health to allow testing of bidirectional relationships to advance understanding of what effect precedes the other.

The present study contributes to this stream of research by investigating whether there are bidirectional relationships between perceptions of procedural justice and three indicators of health: self-rated health, a strong predictor of morbidity and longevity (Idler \& Benyamini, 1997); depressive symptoms, an indicator of mental well-being; and sickness absence, a behavioral consequence with high costs for both individuals and organizations (Black \& Drost, 2011). The use of a variety of health indicators thus offers a more comprehensive view on how justice relates to different indicators of health. Furthermore, a particular contribution of this study is that we investigate relationships with a full panel design over three time points, with data roughly representative of the Swedish population. We, therefore, systematically investigate the potential existence of reversed effects between organizational justice perceptions and health.

Although direct effects between justice perceptions and indicators of health have gained empirical support (Robbins et al., 2012), rather limited attention has been given to the underlying processes. Lack of research in this area presents a significant gap. Many different potential mechanisms for explaining the organizational justice-health relationship have been put forward, but empirical studies testing these relationships are scarce (Eib, von Thiele Schwarz, \& Blom, 2015; Elovainio, Kivimäki, Vahtera Keltikangas-Järvinen, \& Virtanen, 2003; Judge \& Colquitt, 2004; Manville, Akremi, Niezborala, \& Mignonac, 2016). Building on the allostatic load model (McEwen, 2008), we argue for a mediating effect of mental preoccupation with work (a cognitive state characterized by obtrusive work-related thoughts). Therefore, our second contribution is to add to the literature by testing one underlying process for the relationship from organizational justice perceptions to indicators of health. Moreover, studies about underlying processes to explain relationships from health to justice are missing. Building on the affective perception and reaction assumption (Lang et al., 2011), we propose a mediating effect of social support at work for the potential effects from health indicators to organizational justice perceptions. The approach of testing processes for reversed effects in occupational health is novel and a third contribution of this article, as it adds to the understanding of how organizational justice and health as well as health and organizational justice impact each other.

\section{Theory and Hypotheses}

Researchers have theorized on the justice-health relationship using classical justice theories such as equity theory (Greenberg, 2010; Kalimo, Taris, \& Schaufeli, 2003), uncertainty management model (Elovainio et al., 2005; Judge \& Colquitt, 2004), groupvalue model (De Boer, Bakker, Syroit, \& Schaufeli, 2002; Howard \& Cordes, 2010), and fairness theory (Fujishiro \& Heaney, 2009). Other researchers have made use of stress theories such as trans- actional stress theory (Greenberg, 2004; Lang et al., 2011; Spell \& Arnold, 2007; Tepper, 2001), effort-recovery model (Manville et al., 2016), or the allostatic load model (Eib et al., 2015; Elovainio et al., 2009). However, despite the diversity of paradigms framing the majority of the justice-health research, most theories clearly point out (in)justice as the cause and health (problems) as the consequence, whereas few explanations have been put forward for the alternative direction of health as a cause of justice perceptions (for an exception, see Lang et al., 2011).

Organizational justice refers to employees' fairness perceptions at the workplace regarding the perceived fairness of the allocation of resources (distributive justice), fairness of the decision-making processes (procedural justice), and the treatment and explanations employees receive from organizational representatives (interpersonal and information justice; Colquitt, 2001). In this article, we focus on procedural justice as one of the structural elements of justice, as procedural justice tends to be attributed to decisions and processes by the organization (Rupp \& Cropanzano, 2002). Procedural justice has a prominent role in theory (Thibaut \& Walker, 1975; Tyler \& Blader, 2003) and empirical studies (Colquitt et al., 2013). Procedural justice is also the most often studied justice dimension in the justice-health literature (Robbins et al., 2012). In the following subsections, we first focus on the relationship between organizational justice and health before elucidating on the relationship between health and organizational justice.

\section{How Justice Perceptions Influence Health}

Just like perceptions of justice have been found to relate positively to health, low justice perceptions have been regarded as a relevant workplace stressor (Vermunt \& Steensma, 2001) that can cause health problems and strain (Ganzel, Morris, \& Wethington, 2010). Low procedural justice can elicit perceptions of unpredictability and powerlessness. Also, perceptions of low procedural justice are likely to trigger anxiety, as procedural justice perceptions relate to employees' self-esteem and self-evaluations of one's standing in the organization (Blader \& Tyler, 2009). Furthermore, as procedural justice tends to be intrinsic to organizational processes and cannot easily be evaded, we argue that low procedural justice is a stressor of prolonged nature, and thus, is likely to affect a variety of indicators of impaired health in a long-term manner.

In the occupational health literature, two mechanisms have been discussed as underlying the causal relation between stressors at work and health: the psychophysiological and the behavioral lifestyle mechanism (Kompier \& Taris, 2011). The first one holds that long-term exposure to low organizational justice undermines recovery and health through sustained activation of bodily systems. The second one suggests that stressors at work undermine selfcontrol, which increases negative health behaviors such as alcohol intake, smoking, or a sedentary lifestyle. Empirically, there is some evidence for the psychophysiological pathway to explain how justice relates to health over time (Eib et al., 2015; Elovainio et al., 2003; Manville et al., 2016), whereas health behaviors as a mediator between justice perceptions and health has not been empirically supported (Elovainio et al., 2003). We, therefore, focus on the psychophysiological explanation of the justice-health relationship.

The allostatic load model has been described as "the dominant theoretical perspective in stress physiology" (Ganster \& Rosen, 
2013, p. 1086), as it underlines the process by which psychosocial stressors translate into physical and mental harm over time. When a current stressor activates the physiological system, the body accommodates its parameters to adjust to the environment, a process called "allostatis" (McEwen, 2000). Allostatic processes can have a short-term impact on psychological, physiological, and psychosomatic systems, which in itself is not harmful. However, the new balance of system parameters following stressor exposure comes at a physiological cost, called "allostatic load." The allostatic load model holds that harm is done to the body, if this activation of bodily systems is sustained, like under conditions of repeated or chronic stress. In other words, continuous or repeated stressors can have negative consequences in the long run, as they may build up allostatic load, which impacts the immune system, cardiovascular system, and metabolic system, and can lead to psychological disorders like depression (Ganster \& Rosen, 2013; Juster et al., 2011).

As such, cognitive processes play an important role in sustained activation of bodily systems (Brosschot, Pieper, \& Thayer, 2005). The activation of a stressor can be prolonged if a person does not let go of, for instance, negative work-related thoughts. The term mental preoccupation with work refers to such a cognitive state of anxiety about future events (i.e., worry and anticipatory stress) and rumination in the context of work (Eib et al., 2015). We argue that mental preoccupation with work is elicited by low justice perceptions, which produce allostatic load over time, which, in turn, increases the risk for impaired health. Mental preoccupation with work is a concept that taps into the prolongation of the mental representation of a stressor, which makes it similar to concepts such as perseverant cognitions (Brosschot, Gerin, \& Thayer, 2006) and, the opposite, psychological detachment (Sonnentag, 2012). Empirically, Eib et al. (2015) showed that overall organizational justice perceptions related to mental preoccupation with work 1 year later and that mental preoccupation with work mediated the relationship between organizational justice and mental health. Similarly, Elovainio et al. (2009) argued that low justice perceptions may affect health through prolonged activation of the stress response. Moreover, Manville et al. (2016) highlighted the important mediating role of ruminating and worrying thoughts for the association between justice perceptions and recovery.

Procedural justice fulfills two important purposes: selfevaluation and predictability. Self-evaluation refers to the notion that low procedural justice can elicit negative evaluations about one's standing, value, and self-esteem (Tyler \& Blader, 2003). Procedural justice also has an instrumental value because employees are not only more likely to get a voice but also to predict according to which rules decisions are made at the workplace. In addition, employees use procedural justice to gauge whether to trust organizational authorities (van Prooijen, 2009). Therefore, low procedural justice constitutes a workplace stressor that may elicit a state of being unable to withdraw from work. Recent studies on recovering from injustice (Barclay \& Saldanha, 2016; Barclay \& Skarlicki, 2009) suggest that employees linger on their justice perceptions for a long time. In sum, for the relationship between organizational justice and health, we predict:

Hypothesis 1: There is a time-lagged effect of procedural justice on $(a)$ self-rated health, $(b)$ depression, and $(c)$ sickness absence.
Hypothesis 2: Mental preoccupation with work mediates the time-lagged effect of procedural justice on (a) self-rated health, $(b)$ depression, and $(c)$ sickness absence. Specifically, there is a significant indirect effect of procedural justice at T1 through mental preoccupation with work at $\mathrm{T} 2$ to the three health indicators at $\mathrm{T} 3$.

\section{How Health Influences Justice Perceptions}

Most of the available research on organizational justice and health points to low justice perceptions as a work stressor that can result in health problems. Although this perspective is generally accepted and empirically well established, it is also plausible that health outcomes may affect perceptions of justice. Few studies, often with only two measurement points, have investigated the so-called reversed effects, from health indicators to organizational justice perceptions, and findings are mixed. Elovainio et al. (2015) found no relationships from justice perceptions to psychological distress and sleep problems over the course of 4 years, and this is in line with another earlier study from Finland (Kivimäki et al., 2003). Other studies report some indications of causality from justice perceptions to health outcomes, although effect sizes were small (Elovainio et al., 2003) and evidence was not consistent across justice facets and outcomes (Ybema \& van den Bos, 2010). Another study found a relationship from poor health to procedural justice, but not for interactional justice when the follow-up time was several years (Elovainio et al., 2013). Finally, one study reported consistent effects from justice to health outcomes across justice dimensions, but these had been studied over a shorter follow-up time frame of 3-6 months (Lang et al., 2011).

In the occupational health literature, two basic mechanisms have been discussed to explain the "reverse" effects from health to work stressors: Health status triggers a different perception of the same work environment and/or health status triggers a real change in the work environment (de Lange, Taris, Kompier, Houtman, \& Bongers, 2005; Kompier \& Taris, 2011; Tang, 2014). Similar to the two mechanisms described in the work stress literature, Lang et al. (2011) put forth the "affective perception" and "affective reaction" assumptions to explain the relationship between health and organizational justice perceptions.

Changes in perceptions of the work environment are likely, as more fatigued employees perceive their work environment more negatively over time and report higher job demands and lower levels of supervisor social support across time (De Lange, Taris, Kompier, Houtman, \& Bongers, 2004). This perception effect was termed true strain-stressor process (Zapf, Dormann, \& Frese, 1996) or stressor creation hypothesis (Spector, Zapf, Chen, \& Frese, 2000). The perception effect assumes that unhealthy workers perceive their work environment as more "gloomy" over time, whereas healthy workers color their work environment perceptions as more "rosy" over time. As Tang (2014) wrote, "healthy workers are more likely to re-interpret their jobs positively over time as they are able to maintain engaged in their work, accumulate, and conserve job resources (eg, develop good rapport with coworkers), and ultimately, increase job proficiency" (p. 442). Unhealthy workers, on the other hand, perceive their job demands as more exhausting, may have less positive mood and affect toward others, and may have a tendency to recall negative information. The "affective perception assumption" (Lang et al., 2011) pro- 
poses that individuals with impaired health, psychological distress, and depressive symptoms view their work environment, and specifically justice at the workplace, more negatively. In line with this, research shows that perceptions of justice are influenced by psychological states and well-being; for instance, individuals in a negative mood are more likely to perceive unfairness (van den Bos, 2003).

The change of situation explanation suggests that the behavior of unhealthy individuals creates a worse work environment over time (Kompier \& Taris, 2011). The argument is that individuals with reduced health tend to express negative affect (anger, frustration, and disappointment) to coworkers, supervisors, and other organizational members, as well as make use of emotion-focused coping strategies. Depressed or emotionally exhausted individuals are likely to withdraw from others, which undermines a successful development of positive social rapport with coworkers and supervisors (Daniels \& Guppy, 1997; Tang, 2014). Such behavior, in turn, may lead organizational members to avoid these individuals and, as a result, employees with health problems may feel a lack of support and perceive their work environment and organizational authorities as less fair. Research shows that sick people are perceived differently only based on their nonverbal behavior, for example, the way they look like or how they walk (Sundelin et al., 2015). The "affective reaction" assumption (Lang et al., 2011) suggests that health may undermine fairness perceptions because the work environment has actually changed due to colleagues and supervisors reacting to the unhealthy individual. Few have tested these two mechanisms against each other, but evidence suggests that both ideas have merit (de Lange et al., 2005). Over the course of 2 years, both the perception and the change explanation are relevant and are difficult to distinguish from one another.

Regarding explaining the potential reversed effects from health to justice, we predict social support plays a vital role. It has been suggested that healthy individuals have better chances of getting promoted, getting recruited in better jobs, and receiving more support or more interesting tasks (De Lange et al., 2004). Moreover, unhealthy individuals may underperform and, as a result, receive less support from colleagues, or unhealthy individuals may isolate themselves, and in return get less involved, have less information or options at work to voice their opinion (De Lange et

AQ: 4 al., 2004; Kompier \& Taris, 2011), For sickness absence, the link to social support and perceptions of justice may be most apparent. Being absent frequently or for a longer time may mean that colleagues have to cover and take on extra work and, thus, may view the absent worker as less valuable to their team. Decisions are made without involving the individuals on sick leave, who, upon return to work, may feel less knowledgeable, less involved, and less in control over essential procedures at work. In other words, social support may play a mediating role, helping to understand the relationship from health to organizational justice over time. Although the mediation link between health and justice through social support has not been tested before, there is some earlier evidence supporting our prediction. Previous research has shown that depressive symptoms may influence later perceptions of social support at work (Magnusson Hanson, Chungkham, Åkerstedt, \& Westerlund, 2014). In a cross-lagged model, Ibrahim, Smith, and Muntaner (2009) found that self-rated health, depression, and psychological distress were predictive of social support over 2 years. Several studies found "reversed" effects from various health indicators to social support (De Lange et al., 2004; Firth-Cozens \& Hardy, 1992; Melamed, Armon, Shirom, \& Shapira, 2011). In sum, for the relationship between health and organizational justice, we therefore predict:

Hypothesis 3: There is a time-lagged effect of $(a)$ self-rated health, $(b)$ depression, and $(c)$ sickness absence on procedural justice.

Hypothesis 4: Social support at work mediates the timelagged effect of procedural justice on $(a)$ self-rated health, (b) depression, and (c) sickness absence. Specifically, there is a significant indirect effect of procedural justice at T1 through social support at work at T2 to the three health indicators at $\mathrm{T} 3$.

\section{Sample and Procedures}

The study population consisted of the participants of the SLOSH (Swedish Longitudinal Occupational Survey of Health) study-a longitudinal cohort survey with a focus on the association between work organization, work environment, and health. SLOSH started in 2006, for which a representative sample of the Swedish working population was invited to participate. Since then, questionnaires have been administered every second year, following the original SLOSH participants, but also adding new participants over time (open cohort design). Response rates varied between the waves but always exceeded $50 \%$, and today, the total SLOSH data consist of 40,877 individuals. Both SLOSH and the present study have been approved by the Regional Research Ethics Board in Stockholm.

Participants are followed by means of postal questionnaire in two versions, one for those currently in paid work and one for those permanently or temporarily outside the labor force. The current article included participants who responded to the questionnaire for those in paid work in 2010, 2012, and $2014(N=$ 4,079). After exclusion of self-employed and farmers and those who had answered less than three items of the procedural justice or depressive symptoms items, the study sample consisted of 3,236 participants. Of these, $58 \%$ were women, the average age was 48.83 years $(S D=8.57$, range: $22-71), 44 \%$ had a university degree, and $57 \%$ were married or cohabiting.

Comparing those who answered the questionnaire for working people in 2010 and who were followed through all three waves with those who answered the questionnaire for working people in 2010 but were not followed through all three waves due to missing data, we found that slightly more of the eligible participants were women $(56.43 \%$ vs. $43.57 \%, p<.01)$ and had a university degree (40.06 vs. 32.46, $p<.001$ ). Also, included participants were younger (48.67 vs. 50.35, $p<.001)$ and experienced slightly less procedural justice at baseline (3.26 vs. $3.40, p<.001)$. No differences were found with regard to marital status, self-rated health, depressive symptoms, or sickness absence.

\section{Measures}

Procedural justice was assessed by seven items reflecting whether the decision-making procedures at the workplace are accurate, correctable, and consistently applied and whether the 
procedures include opinions from the people involved (Moorman, 1991). Example items are "Decisions are taken on the basis of correct information" or "Bad decisions can be revoked or changed." Responses were given on a 5-point scale ranging from 1 (totally agree) to 5 (totally disagree). Thus, higher values reflect perceptions of low procedural justice, Cronbach's $\alpha$ : .90 (2010), .91 (2012), and .90 (2014).

Mental preoccupation with work was operationalized with two items from the Siegrist et al. (2004) subscale to measure inability to withdraw from work ("As soon as I get up in the morning I start thinking about work problems" and "When I get home, I can easily relax and 'switch off' (reverse coded)"). Responses were given on a 4-point scale ranging from 1 (totally disagree) to 4 (totally agree). These items reflect involuntary preoccupation with work, bivariate correlation: .55 (2010), .57 (2012), and .55 (2014).

Social support was assessed with two items from the demandcontrol-support questionnaire (Theorell et al., 1988) reflecting a supportive work environment ("There is good collegiality at work" and "My coworkers are there for me"). Responses were given on a 4-point scale ranging from 1 (totally agree) to 4 (totally disagree). Thus, higher values reflect perceptions of low social support at work, bivariate correlation: .65 (2010), .65 (2012), and .63 (2014).

Self-rated health was measured with a single item ("How would you rate your general state of health?") answered on a 5-point scale ranging from very good to very bad. Thus, higher values indicate worse health. The validity and reliability of this item have been shown in various studies, and the item is considered a reliable and valid global health measure (Idler \& Benyamini, 1997).

Depressive symptoms were measured with a brief validated subscale from the Hopkins Symptom Checklist, the Symptom Checklist-core depression (Magnusson Hanson, Westerlund, et al., 2014). After an introduction phrase stating "How much during the last week have you been troubled by. .." six core symptoms of depression are mentioned, for example, "Lethargy or low in energy" or "Feeling blue." The participants were asked to respond on a 5-point scale ranging from 1 (not at all) to 5 (extremely). Higher values reflect higher depression severity, Cronbach's $\alpha: .90$ (2008), .90 (2010), and .90 (2012).

Sickness absence was measured with one question about how many days in total the person had been on sick leave during the past 12 months. Responses are given on a 5-point scale with the following response options: None, 1-7 days, 8-30 days, 31-90 days, and 91 days or more.

\section{Results}

Descriptive statistics, correlations, and internal reliabilities are T1, presented in Table 1. Internal reliabilities were excellent and correlations were all in the expected direction. In line with recommendations (Little, Preacher, Selig, \& Card, 2007), we analyzed our cross-lagged panel design with structural equation modeling techniques.

\section{Measurement Invariance}

Before testing the hypotheses, we examined configural and metric invariance for the latent variables (procedural justice, mental preoccupation with work, social support, and depressive symp-

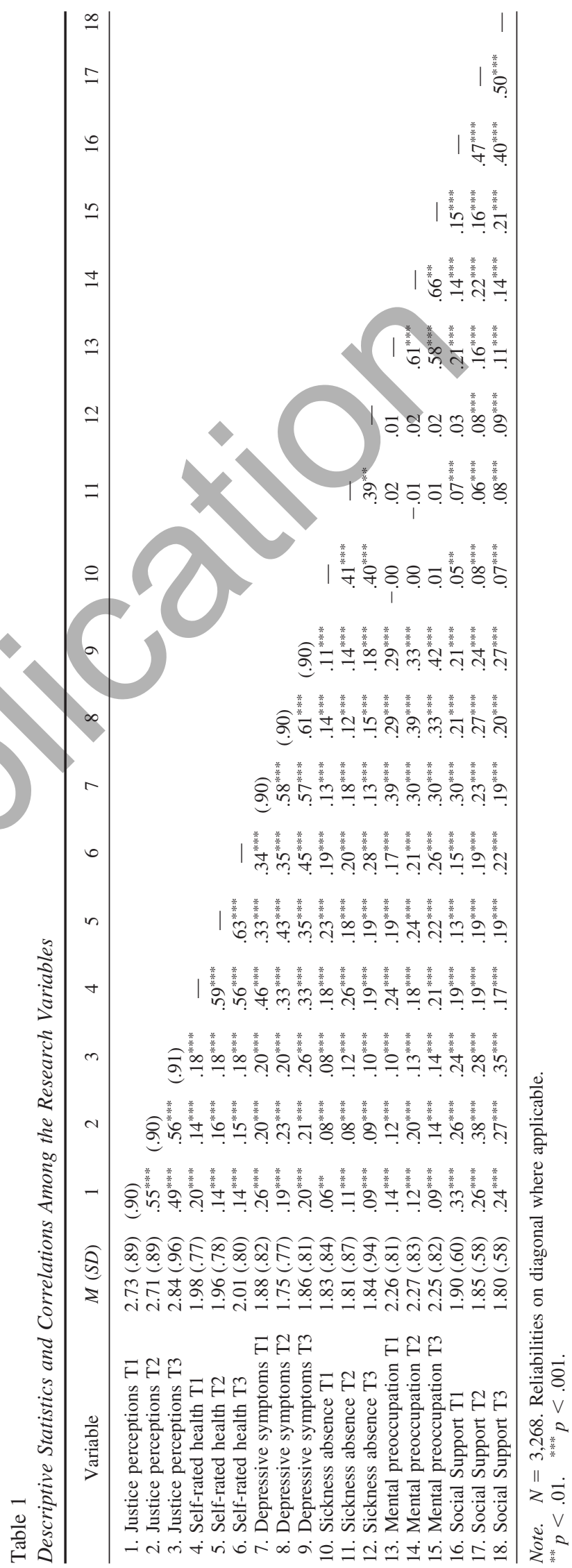


toms) to make sure our hypotheses could be tested accurately (Vandenberg \& Lance, 2000). Following recommendations in the literature (Cole \& Maxwell, 2003; Little et al., 2007), the measurement errors of the same item over time were allowed to correlate.

Specifying the same factor structure at T1, T2, and T3 for procedural justice perceptions provided an acceptable fit to the data $\left(\chi^{2}=1,524.89, d f=183\right.$, comparative fit index $[\mathrm{CFI}]=.967$, root mean square error of approximation [RMSEA] $=.048$, standardized root mean squared residual [SRMR] $=.024$ ), as did setting the factor loadings of all items to be equal across the three time points $\left(\chi^{2}=1,538.94, d f=195\right.$, CFI $=.967$, RMSEA $=$ $\left..046, \mathrm{SRMR}=.025, \Delta \chi^{2}=14.05, \Delta d f=13, p=n s\right)$. For mental preoccupation with work and social support, the model fit for configural invariance was excellent $\left(\chi^{2}=0.35, d f=3\right.$, CFI $=$ 1.00, RMSEA $=.000$, SRMR $=.001$ and $\chi^{2}=5.48, d f=3$, $\mathrm{CFI}=1.00, \mathrm{RMSEA}=.016, \mathrm{SRMR}=.005)$. The models did not significantly worsen when testing metric invariance $\left(\chi^{2}=3.18\right.$, $d f=5, \mathrm{CFI}=1.00, \mathrm{RMSEA}=.000, \mathrm{SRMR}=.007, \Delta \chi^{2}=2.83$, $\Delta d f=2, p=n s$ and $\chi^{2}=6.77, d f=5, \mathrm{CFI}=1.00$, RMSEA $=$ $\left..010, \mathrm{SRMR}=.006, \Delta \chi^{2}=1.29, \Delta d f=2, p=n s\right)$. For depressive symptoms, the model fit was acceptable $\left(\chi^{2}=2,162.64, d f=129\right.$, $\mathrm{CFI}=.950, \mathrm{RMSEA}=.069, \mathrm{SRMR}=.038)$, and setting the loadings of the items equal across time did not change the fit significantly $\left(\chi^{2}=2,178.05, d f=139, \mathrm{CFI}=.950, \mathrm{RMSEA}=\right.$ .067, SRMR $\left.=.038, \Delta \chi^{2}=15.41, \Delta d f=10, p=n s\right)$. To summarize, results provided evidence for metric measurement invariance over time for procedural justice perceptions, mental preoccupation with work, social support, and depressive symptoms.

\section{Conceptual Model Testing}

After confirming the adequacy of the measurement model, we T2, specified and tested the different structural models (see Tables 2, 3 , and 4). Direct effects were tested by estimating the two lagged effects over time, for instance, from justice perceptions at T1 (T2) to a health indicator at T2 (T3). Mediation was tested by estimating the longitudinal path $a$ (for instance, from a health indicator at T1 to the mediator social support at T2) and the longitudinal path $b$ (for instance, from social support at T2 to procedural justice at T3). Furthermore, we examined the significance of the indirect effects, the product of path $a$ and path $b$, and the bias-corrected confidence intervals (CIs) of the indirect effects generated by bootstrap procedures based on 5,000 samples.
To set the independent and dependent variables on one metric, self-rated health and sickness absence were translated into latent variables. Specifically, these latent variables had one single indicator with the residual variances fixed to $(1-$ reliability $) \times$ sample variance (Hayduk, 1987). As is often done, we assumed a reliability of .70 (Wanous, Reichers, \& Hudy, 1997). Furthermore, the analyses involving self-rated health and sickness absence were tested with the robust maximum likelihood estimator in Mplus. Analyses involving depressive symptoms were computed with the maximum likelihood estimator. Model fit (Hu \& Bentler, 1995) was assessed with CFI, RMSEA, and SRMR. Differences in model fit were assessed based on the chi-square difference test for nested models. We used the full-information maximum likelihood technique to deal with missing values in the variables. Full-information maximum likelihood provides unbiased and efficient estimates and is recommended in the literature (Enders \& Bandalos, 2001).

Model 1 included the temporal stability effects between the constructs. For instance, procedural justice at $\mathrm{T} 1$ was specified to predict procedural justice at $\mathrm{T} 2$ and at $\mathrm{T} 3$, and procedural justice at $\mathrm{T} 2$ was set to predict procedural justice at T3. At T1, procedural justice, the two mediators (mental preoccupation with work and social support), and the respective health indicator (self-rated health, depressive symptoms, or sickness absence) were set to correlate freely. The error covariances between concepts (procedural justice, the two mediators, and the respective health indicator) between T2 and T3 were estimated freely. All the stability effects (also called autoregressive effects) were significant and in the predicted direction.

Model 2 extended Model 1 by adding the two cross-lagged effect from procedural justice perceptions on the respective health indicator. To achieve a more parsimonious model and a simpler interpretation, the lagged effects were constrained to be equal. For self-rated health, Model 2 did not fit better than Model 1, indicating that the addition of the cross-lagged effects is not meaningful in predicting self-rated health over time, whereas for depressive symptoms and sickness absence, Model 2 fitted better than Model 1.

Model 3 extended Model 2 by adding the paths from procedural justice at T1 (T2) to mental preoccupation with work at T2 (T3) and from mental preoccupation with work at $\mathrm{T} 1$ (T2) to the respective health indicator at T2 (T3). Again, the lagged effects were constrained to be equal. Model 3 fitted better than Model 2 for all health indicators.

Table 2

Fit Table for Justice Perceptions and Self-Rated Health

\begin{tabular}{|c|c|c|c|c|c|c|c|}
\hline Model comparisons & $x^{2}$ & $d f$ & CFI & RMSEA & SRMR & $\Delta \chi^{2}$ & $\Delta d f$ \\
\hline Model 1: Stability effects & $1,939.31$ & 534 & .973 & .029 & .033 & - & - \\
\hline Model 2: M1 + PJ $\rightarrow$ SRH & $1,939.46$ & 533 & .973 & .029 & .033 & M2 vs. M1: .03* & 1 \\
\hline Model 3: M2 + PJ $\rightarrow$ MP, MP $\rightarrow$ SRH & $1,938.93$ & 531 & .973 & .029 & .033 & M3 vs. M2: $.53^{*}$ & 2 \\
\hline Model 4: M3 + SRH $\rightarrow$ PJ & $1,921.21$ & 530 & .974 & .028 & .030 & M4 vs. M3: $19.21^{* * *}$ & 1 \\
\hline Model 5: M4 $+\mathrm{SRH} \rightarrow \mathrm{SS}, \mathrm{SS} \rightarrow \mathrm{PJ}$ & $1,842.27$ & 528 & .975 & .028 & .023 & M5 vs. M4: $78.94^{* * *}$ & 2 \\
\hline
\end{tabular}

Note. $\quad N=3,236 ; d f=$ degrees of freedom; CFI = comparative fit index; RMSEA = root mean square error of approximation; SRMR = standardized root mean square residual; M1-M5= Models $1-5$; PJ = procedural justice; SRH = self-rated health; MP = mental preoccupation with work; SS = social support.

${ }^{*} p=n s . \quad * * p<.05$. 
Table 3

Fit Table for Justice Perceptions and Depressive Symptoms

\begin{tabular}{|c|c|c|c|c|c|c|c|}
\hline Model comparisons & $\chi^{2}$ & $d f$ & CFI & RMSEA & SRMR & $\Delta \chi^{2}$ & $\Delta d f$ \\
\hline Model 1: Stability effects & $4,661.27$ & 1143 & .964 & .031 & .039 & - & - \\
\hline Model 2: M1 + PJ $\rightarrow$ D & $4,645.28$ & 1142 & .964 & .031 & .035 & M2 vs. M1: $15.99^{*}$ & 1 \\
\hline Model 3: M2 + PJ $\rightarrow$ MP, MP $\rightarrow$ D & $4,613.72$ & 1140 & .965 & .031 & .034 & M3 vs. M2: $31.56^{*}$ & 2 \\
\hline Model 4: M3 + D $\rightarrow$ PJ & $4,596.33$ & 1139 & .965 & .031 & .031 & M4 vs. M3: $17.39^{*}$ & 1 \\
\hline Model 5: M4 + D $\rightarrow$ SS, SS $\rightarrow$ PJ & $4,549.67$ & 1137 & .965 & .030 & .027 & M5 vs. M4: 46.66* & 2 \\
\hline
\end{tabular}

Note. $\quad N=3,236 ; d f=$ degrees of freedom; CFI = comparative fit index; RMSEA $=$ root mean square error of approximation; SRMR $=$ standardized root mean square residual; M1-M5 = Models $1-5 ; \mathrm{PJ}=$ procedural justice; $\mathrm{D}=$ depressive symptoms; $\mathrm{MP}=$ mental preoccupation with work; $\mathrm{SS}=$ social support.

$* p<.05$.

Model 4 extended Model 3 by including the two cross-lagged effects of the respective health indicator on justice perceptions. Again, the lagged effects were constrained to be equal. Model 4 fitted better than Model 3 for all health indicators.

Model 5 extended Model 4 by adding the paths from the respective health indicator at T1 (T2) to social support at T2 (T3) and from social support at T1 (T2) to procedural justice at T2 (T3). Again, the lagged effects were constrained to be equal. This model was the best fitting model for all health indicators. Estimates from Model 5 are displayed in Figures 1, 2, and 3 for all three health indicators.

Hypothesis 1 predicted a significant time-lagged effect from justice perceptions to the three health indicators. For self-rated health, Model 2, which included the lagged effects, did not fit better than Model 1 without these lagged paths $\left(\Delta \chi^{2}=.03, \Delta d f=\right.$ $1, p=n s$ ). In addition, the estimates from Model 5 (as displayed in Figure 1) show that procedural justice at T1/T2 did not have significantly time-lagged effects to self-rated health at T2/T3 $(\beta=-.00, n s)$. For depressive symptoms, Model 2 fitted better than Model $1\left(\Delta \chi^{2}=15.99, \Delta d f=1, p<.05\right)$, and estimates from Model 5 (as displayed in Figure 2) reveal that procedural justice at $\mathrm{T} 1 / \mathrm{T} 2$ was significantly related to depressive symptoms at T2/T3 $(\beta=.03, p<.05)$. For sickness absence, Model 2 fitted better than Model $1\left(\Delta \chi^{2}=26.17, \Delta d f=1, p<.05\right)$, and estimates from Model 5 (as displayed in Figure 3 ) reveal that procedural justice at T1/T2 was significantly related to T2/T3 sickness absence $(\beta=$ $.07, p<.001)$. Together with the findings from the comparative model fit tests, these results provide support for Hypothesis $1 \mathrm{~b}$ and $1 \mathrm{c}$.

Hypothesis 2 predicted that mental preoccupation with work mediates the relationship between procedural justice and health indicators. For self-rated health, Model 3 , which included the mediation paths, did not fit better than Model 2( $\left(\Delta \chi^{2}=.53, \Delta d f=\right.$ $2, p=n s)$. As can be seen from the estimates displayed in Figure 1 , procedural justice at $\mathrm{T} 1$ was not significantly related to mental preoccupation with work at T2 $(\beta=-.01, n s)$, and mental preoccupation with work at T2 was not significantly related to self-rated health at T3 $(\beta=.00, n s)$. Equally, the indirect effect was not significant (effect $=.000, S E=.000, p=.789,95 \% \mathrm{CI}$ $[-.001, .000])$. For depressive symptoms, Model 3, which included the mediation paths, fitted better than Model $2\left(\Delta \chi^{2}=\right.$ 31.56, $\Delta d f=2, p<.05)$. As can be seen from the estimates displayed in Figure 2, procedural justice at T1 was not significantly related to mental preoccupation with work at $\mathrm{T} 2(\beta=-.01$, $n s)$, but mental preoccupation with work at T2 was significantly related to depressive symptoms at $\mathrm{T} 3(\beta=.08, p<.001)$. However, the indirect effect was not significant (effect $=-.001$, $S E=.001, p=.425,95 \%$ CI $[-.003, .001])$. For sickness absence, Model 3 did not fit better than Model $2\left(\Delta \chi^{2}=1.39\right.$, $\Delta d f=2, p=n s)$. As can be seen from the estimates displayed in Figure 3, procedural justice at $\mathrm{T} 1$ was not significantly related to mental preoccupation with work at $\mathrm{T} 2(\beta=-.01, n s)$, and mental preoccupation with work at $\mathrm{T} 2$ was not significantly related to sickness absence at T3 $(\beta=.01, p=n s)$. The indirect effect was also not significant (effect $=.000, S E=.000, p=.584,95 \% \mathrm{CI}$ $[-.001, .000])$. These results do not provide support for Hypothesis 2 .

Hypothesis 3 predicted that there are significant time-lagged effects from health indicators to procedural justice. Adding the lagged effects from self-rated health at T1 (T2) to justice perceptions at T2 (T3) improved model fit for self-rated health significantly $\left(\Delta \chi^{2}=19.21, \Delta d f=1, p<.05\right)$. Self-rated health at T1/T2

Table 4

Fit Table for Justice Perceptions and Sickness Absence

\begin{tabular}{lcccccr}
\hline \multicolumn{1}{c}{ Model comparisons } & $\chi^{2}$ & $d f$ & CFI & RMSEA & SRMR & $\Delta \chi^{2}$ \\
\hline Model 1: Stability effects & $1,894.05$ & 534 & .973 & .028 & .033 & $\Delta d f$ \\
Model 2: M1 + PJ $\rightarrow$ SA & $1,871.15$ & 533 & .974 & .028 & .031 & M2 vs. M1: 26.17** \\
Model 3: M2 + PJ $\rightarrow$ MP, MP $\rightarrow$ SA & $1,869.49$ & 531 & .974 & .028 & .031 & M3 vs. M2: 1.39** \\
Model 4: M3 + SA $\rightarrow$ PJ & $1,853.30$ & 530 & .974 & .028 & .030 & M4 vs. M3: 16.83*** \\
Model 5: M4 + SA $\rightarrow$ SS, SS $\rightarrow$ PJ & $1,800.05$ & 528 & .975 & .027 & .024 & M5 vs. M4: 55.58** \\
\hline
\end{tabular}

Note. $\quad N=3,236 ; d f=$ degrees of freedom; $\mathrm{CFI}=$ comparative fit index; RMSEA $=$ root mean square error of approximation; SRMR $=$ standardized root mean square residual; M1-M5= Models $1-5 ; \mathrm{PJ}=$ procedural justice; $\mathrm{SA}=$ sickness absence; $\mathrm{MP}=$ mental preoccupation with work; $\mathrm{SS}=$ social support.

$* p<n s$. ${ }^{* *} p=.05$. 


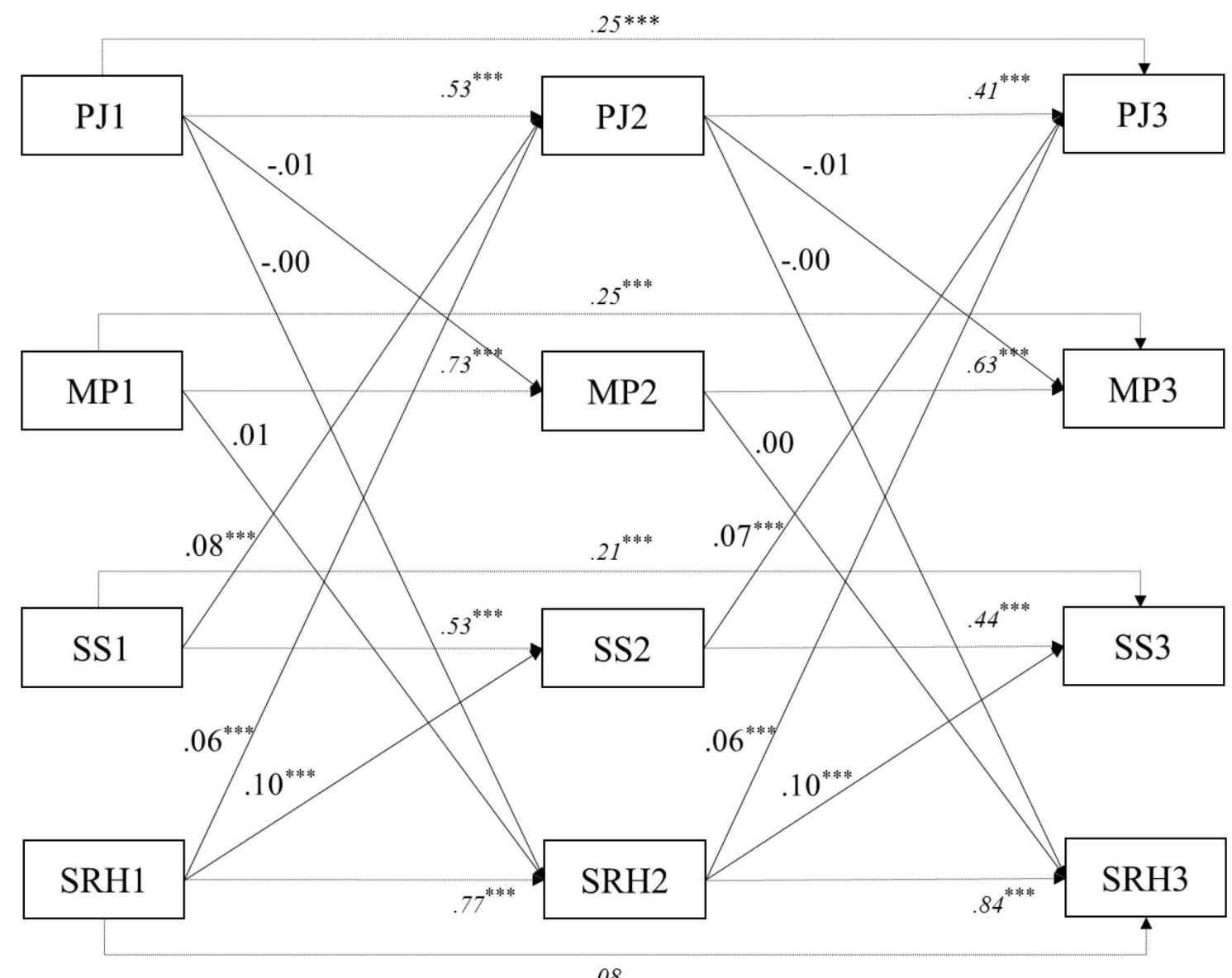

Figure 1. Justice and self-rated health. Standardized estimates displayed (Model 5). PJ = procedural justice; $\mathrm{SRH}=$ self-rated health; MP = mental preoccupation with work; SS $=$ social support. ${ }^{* * * *} p<.001$.

was significantly related to procedural justice at T2/T3 $(\beta=.06$, $p<.001)$. The model for depressive symptoms was also improved with the additional paths $\left(\Delta \chi^{2}=17.39, \Delta d f=1, p<.05\right)$. Similarly, the lagged effects from depressive symptoms to procedural justice were significant $(\beta=.04, p<.05)$. For sickness absence, the model including the lagged effects from sickness absence to procedural justice also fitted better $\left(\Delta \chi^{2}=16.83\right.$, $\Delta d f=1, p<.05)$ and the lagged effects were significant $(\beta=.06$, $p<.001)$. Together, these results provide support for Hypothesis $3 \mathrm{a}, 3 \mathrm{~b}$, and $3 \mathrm{c}$.

Hypothesis 4 predicted that social support mediates the relationship between health indicators and procedural justice. For all health indicators, including the mediation paths improved model fit significantly $(p<.05)$. Self-rated health at T1 was significantly related to social support at $\mathrm{T} 2(\beta=.10, p<.001)$, and social support at T2 was significantly related to procedural justice at T3 $(\beta=.07, p<.001)$. The indirect effect was significant (effect $=$ $.009, S E=.002, p<.05,95 \%$ CI [.005, .013]). Depressive symptoms at $\mathrm{T} 1$ were significantly related to social support at $\mathrm{T} 2$ $(\beta=.05, p<.001)$, and social support at T2 was significantly related to procedural justice at T3 $(\beta=.07, p<.001)$. The indirect effect was significant (effect $=.004, S E=.001, p<.05,95 \% \mathrm{CI}$ $[.002, .007])$. Sickness absence at $\mathrm{T} 1$ was significantly related to social support at T2 $(\beta=.06, p<.001)$, and social support at T2 was significantly related to procedural justice at T3 $(\beta=.08, p<$ $.001)$. The indirect effect was also significant (effect $=.005, S E=$ $.001, p<.05,95 \%$ CI $[.003, .008])$. Together, these results provide support for Hypothesis $4 \mathrm{a}, 4 \mathrm{~b}$, and $4 \mathrm{c}$.

\section{Discussion}

In this study, we sought to provide a clearer understanding of the longitudinal relationship between organizational justice and health. We investigated the bidirectional relationships between procedural justice perceptions and health indicators in a cross-lagged design with three waves of data. Based on the allostatic load model, we argued that mental preoccupation with work mediates the relationship between justice perceptions and different health outcomes. Based on the affective perception and affective reaction assumption, we suggested that health outcomes relate to justice perceptions over time through the impact of social support at work.

Our first contribution relates to the systematic investigation of lagged effects between procedural justice and different indicators of health. Regarding the lagged direct effects from organizational justice to indicators of health, we found significant lagged effects to depressive symptoms and sickness absence but nonsignificant 


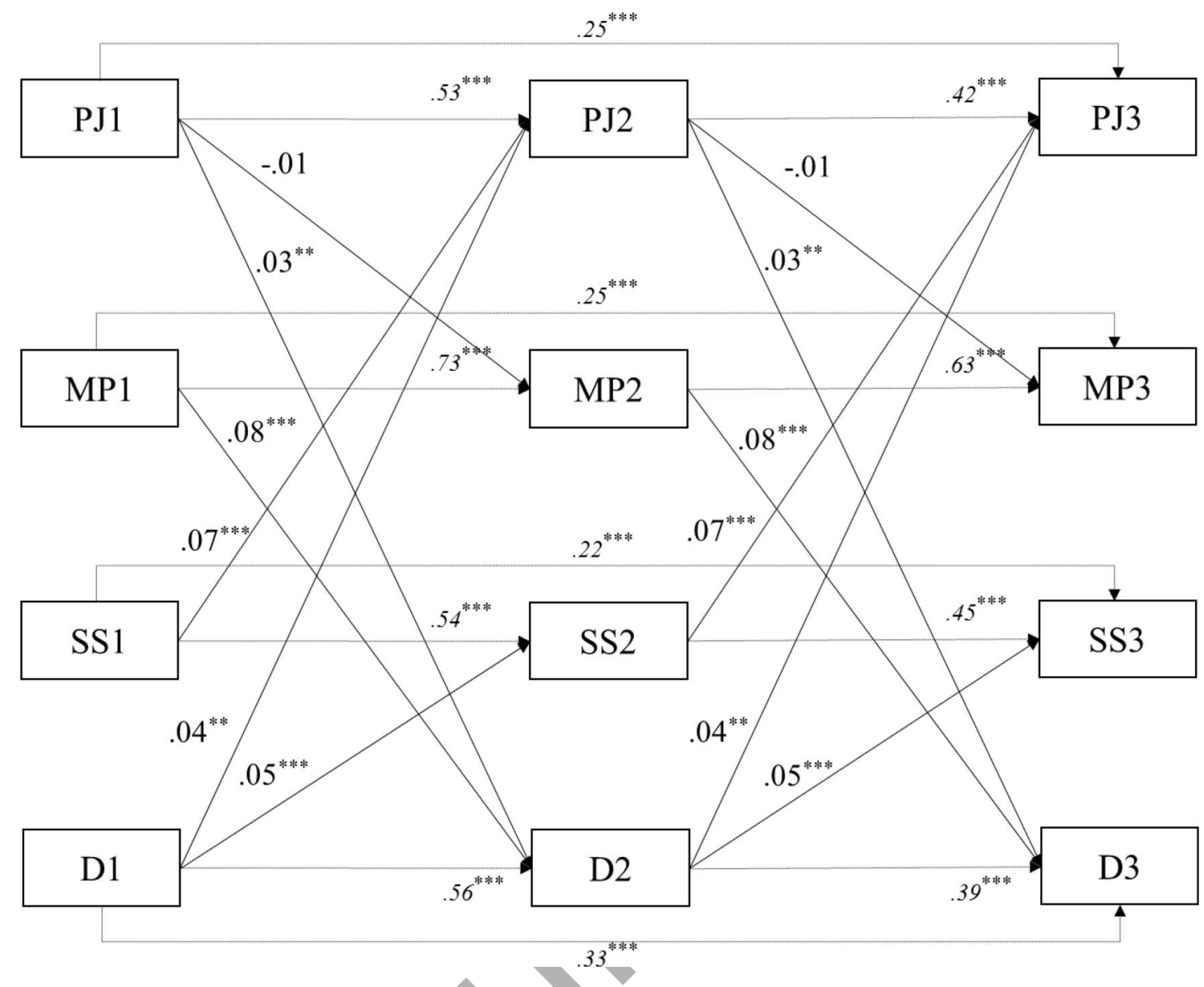

Figure 2. Justice and depressive symptoms. Standardized estimates displayed (Model 5). PJ = procedural justice; $\mathrm{D}=$ depressive symptoms; $\mathrm{MP}=$ mental preoccupation with work; $\mathrm{SS}=$ social support. ${ }^{* * *} p<.01$. ***** $p<.001$.

lagged effects for self-rated health. For interpreting these results, however, it should be taken into consideration that the model for testing the lagged effects included not only autoregressive relationships but also the two proposed mediators. It is possible that justice perceptions influenced health before the study for many workers, and that they had reached a state of adaptation such that continued low justice was not related to a continued decrease in health. Indeed, at all time points, justice perceptions and self-rated health were significantly correlated $\left(r_{\mathrm{T} 1-\mathrm{T} 1}=.20, r_{\mathrm{T} 2-\mathrm{T} 2}=.16\right.$, $r_{\mathrm{T} 3-\mathrm{T} 3}=.18$ ). The results may therefore suggest that (low) justice does not predict any increases (decreases) in self-rated health beyond any initial impact and/or beyond effects that may have occurred before the start of the study. This finding may also indicate that individuals use various aspects of their health when making a summative assessment of their self-rated health status. In addition, the strong autoregressive relationships for self-rated health may have also limited the possibility of predicting additional variance. It would be ideal to follow individuals from the beginning of their working life and test whether individuals with low perceptions of justice reach a state of adaptation or drop out of the labor market over time due to sickness absence or other health problems. In sum, the results show that procedural justice is related to depressive symptoms and sickness absence over time.
Regarding the lagged effects from health to justice, we based our predictions on the affective perception and reaction hypothesis put forward by Lang and colleagues (2011). Consistent with this line of thinking, we found significant longitudinal relationships for all three indicators of health to procedural justice. Thus, the results suggest that over time, feeling unhealthy, having depressive symptoms, and being sickness absent more often have a significant effect on perceiving less procedural justice at work. Results support the effects found by Lang et al. (2011). However, Ybema and van den Bos (2010) found no lagged effects from depressive symptoms and sickness absence to procedural justice. Although Ybema and van den Bos (2010) used a cross-lagged design with three points of data, they did not have a valid measure of procedural justice but instead measured a concept closer to "concern for employees by the organization," which may explain the divergent results. Elovainio et al. (2015) found lagged effects between justice perceptions and mental health but no effects in the other direction. However, Elovainio et al. (2015) only had two time points, had a time lag of 4 years, and took an average of all justice facets, which may hinder comparability with the present study. The reversed effects in the present study were consistently present. Therefore, this study supports notions that health status affects procedural justice perceptions over time. 


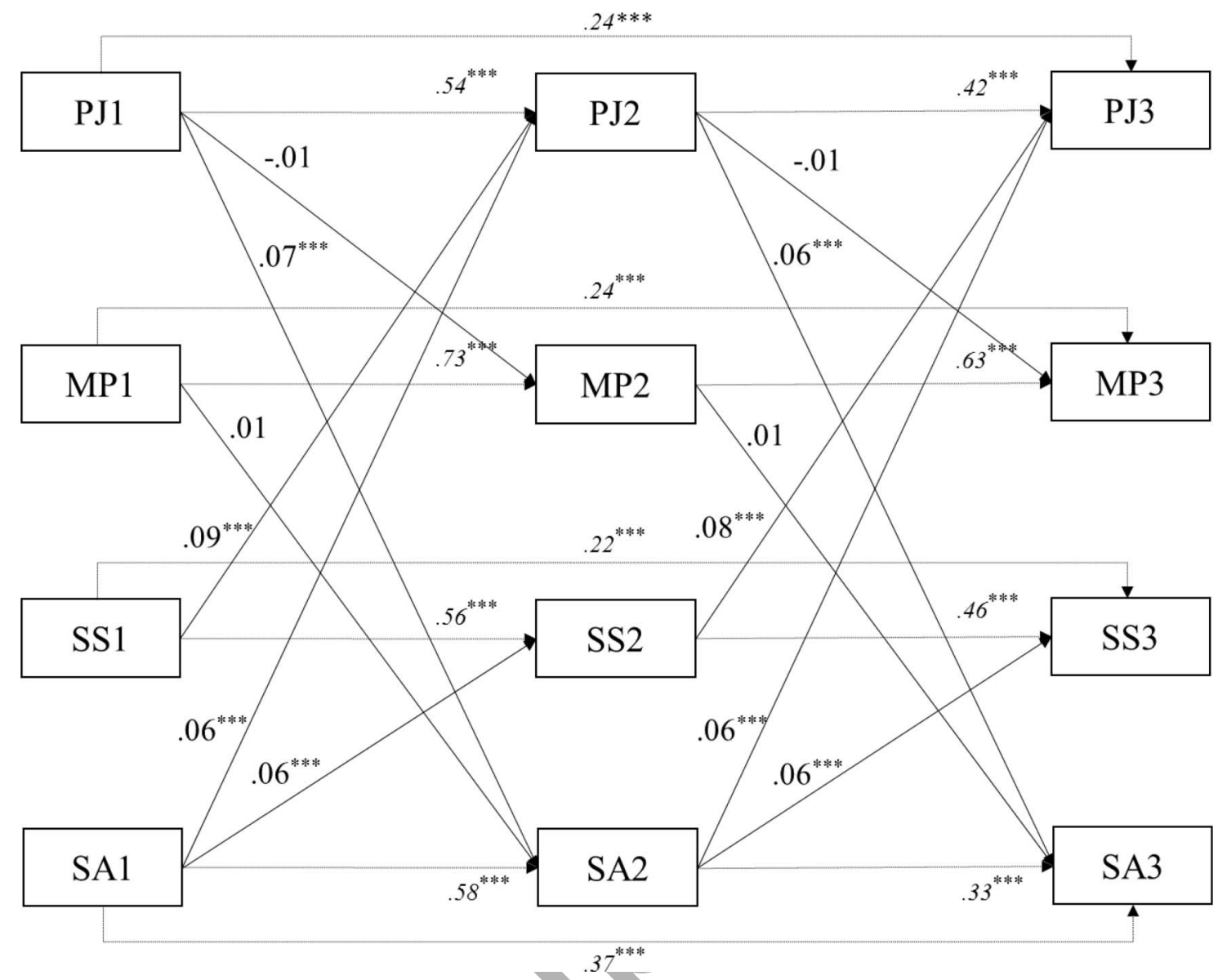

Figure 3. Justice and sickness absence. Standardized estimates displayed (Model 5). PJ = procedural justice; $\mathrm{SA}=$ sickness absence; $\mathrm{MP}=$ mental preoccupation with work; $\mathrm{SS}=$ social support. ${ }^{* * *} p<.01 .{ }^{* * * *} p<.001$.

Our second contribution relates to the process underlying the relationship between organizational justice and health. Apart from some exceptions, there are few empirical studies testing the underlying processes of the justice-health relationship. Contradictory to our expectations, mental preoccupation with work did not mediate the relationship between organizational justice and later health outcomes. There are several potential reasons for these findings. First, the autoregressive effects of mental preoccupation with work were very strong, making it difficult to predict additional variance. Indeed, mental preoccupation with work has both a state and a trait component, and it may be that either the time lag of 2 years or the measurement was not ideal to capture the state component. For instance, previous research has supported the mediating role of mental preoccupation with work for overall justice over a shorter period than the present study (Eib et al., 2015). It is plausible that injustice has an immediate effect on mental preoccupation with work, which then has a delayed impact on health. In further analyses adapting Model 5, we found significant indirect effects between procedural justice at T1/T2 to depressive symptoms at $\mathrm{T} 2 / \mathrm{T} 3$ through mental preoccupation with work at T1/T2 (effect $=.014, S E=.001, p<.001,95 \%$ CI [.009, .020]) but nonsignificant indirect effects for self-rated health (effect $=.001, S E=.002, p=\mathrm{ns}, 95 \%$ CI $[-.004, .005])$ and sickness absence (effect $=.002, S E=.003, p=\mathrm{ns}, 95 \% \mathrm{CI}$ $[-.003, .007])$. Although one cannot tease apart the temporal order among concurrent levels of procedural justice and mental preoccupation with work, these analyses indicate mental preoccupation with work may be indeed a mediator for predicting relationships between work stressors and mental health-related outcomes over time. This underlines the importance of studying mental preoccupation in further studies, ideally with other time intervals to test when effects occur and how long they prevail. Furthermore, it needs to be tested whether mental preoccupation is a mediator for relationships from workplace stressors to mental health problems, as suggested by the further analyses and past research (Eib et al., 2015), or whether effects on overall health and sick leave can be detected with other time lags. Another point relates to the justice facet. Structural components of justice, like procedural justice, may undermine career progression or job insecurity, but also relate to the individuals' sense of standing in the organization. Therefore, one can speculate that the structural components of justice elicit more problem-solving rumination (Querstret \& Cropley, 2012), for example, how to move past the injustice and progress in one's job and make up for the unfair environment or supervisor. Instead, interactional justice, and here particularly interpersonal injustice, which is seen as the "hot" facet of justice (Barsky \& Kaplan, 
2007), may trigger more negative affective rumination, for example, blaming oneself or others or trying to figure out whether the transgression was intentional.

Our third contribution is that the present study fills the gap of better understanding the process by which health relates to justice perceptions over time. We suggested that social support is an important mediator, and results revealed small but significant indirect effects across all three health indicators, such that employees who report lower self-rated health, depressive symptoms, and higher sickness absence were more likely to perceive their work environment as less supportive over time, which, in turn, was associated with lower perceived procedural justice. To our knowledge, this is the first study testing the underlying process of the effects from health to organizational justice. This result is consistent with both the affective reaction and perception assumptions, such that lower social support is received/perceived from coworkers and organizational representatives as reactions to the ill-health of an employee. Further research is needed to distinguish between these two explanations and to study the extent to which they operate simultaneously. The evidence from this study suggests that over time relationships between social support and organizational justice may differ from what is widely assumed: In the justice and work environment literature, organizational justice and social support are often seen as either positive resources that have independent effects on outcomes or interact with each other to predict outcomes (Ndjaboué et al., 2012; Rousseau, Salek, Aubé, \& Morin, 2009). Our study suggests that the occupational health literature may need to revisit the relationship between social support and organizational justice, as, indeed, one effect may precede and thus influence the other over time.

For further research, there is also a need to examine potential moderators of the lagged and mediated effects. One such possible moderator could be job change. Procedural justice most often is considered to stem from the organization, as the organization sets policies and procedures. If employees have changed their jobs, their justice perceptions should also change according to theory (Lind, 2001). However, further analyses of our data, using a multiple group analysis, have shown that this explanation can be ruled out, as job change (with " 0 " meaning that an employee did not change his or her employer and "1" meaning that an employee changed his or her employer at least once over the study period) did not moderate the direct relationships reported in this study. There may also be important moderator variables such as personality for the relationship from health to justice; for instance, employees high on agreeableness and extraversion may trigger more positive reactions from colleagues and supervisors even if they have serious health problems than individuals who are more introverted or less agreeable. It might also be useful to study justice and health relations in multiple countries, as relations may depend on the level of stable welfare support.

\section{Limitations}

Before concluding, we want to highlight some of the limitations of this study. First, a time lag of 2 years is relatively long, although much longer time lags have been studied in the justice literature (Fortin, Cojuharenco, Patient, \& German, 2014). In attempting to calculate optimal time lags, the stability of the concepts is crucial (Dormann \& Griffin, 2015). Fairness heuristics theory (Lind,
2001) suggests that justice perceptions are relatively stable once formed. Based on previous research, one may also argue that health is relatively stable over time. These considerations may lend itself to study justice and health relationships over a longer period than, for instance, justice and work-related concepts. As justice and health are dynamic concepts and mixed findings exist, it is currently unclear when and how long it takes for the effects to appear and disappear (Roe, 2008). Future research could build on the different stress reaction and stress adaptation models that have been suggested (Frese \& Zapf, 1988) to model the impact of organizational justice and health (and vice versa) depending on different time lags. Although the literature would profit from investigating different time lags for better understanding the justice-health and health-justice relationship, it may be challenging to implement short time lags in nationally representative survey studies.

A second limitation is that we concentrated our efforts on procedural justice perceptions, ignoring other facets of organizational justice. However, procedural justice is a highly important dimension and relates to the structural aspects of organizational decision-making. Relationships between outcomes and other facets of justice, like interactional justice, may be less strong over time, as it relates to specific supervisors, who might change over the course of the study period. In future research, it may be particularly valuable to study overall justice, as it may provide a better match of the generality to an overall perception of self-rated health (Ambrose \& Schminke, 2009).

A further limitation is that sickness absence was measured as self-report and not in an objective manner. However, data treatment was confidential, which should help undermine biases and results for sickness absence were similar to the other outcomes. Also, several European studies report a relatively good agreement between self-reported and recorded days of sickness absence (Fredriksson, Toomingas, Torgén, Thorbjörnsson, \& Kilbom, 1998), and a study among Canadian public employees found a correlation of .89 between self-reported and employer-recorded sickness absence, suggesting that self-reports of sickness absence can be fairly accurate (Caverley, Cunningham, \& MacGregor, 2007). Future research could also study objective sickness absence in a cross-lagged manner.

There are notions that cross-lagged designs include control for previous levels of variables, thereby innately controlling for the influence of background variables (Zapf et al., 1996). Nevertheless, we extended Model 5 by the covariates age, sex, and education. Consistent with one of the approaches to include covariates (Little et al., 2007), we controlled for the effects of the covariates on the first measurement occasion. Specifically, age, sex, and education at $\mathrm{T} 1$ were set to predict justice perceptions, mental preoccupation with work, social support, and the respective health indicator at T1. The estimates for the paths were similar (not displayed) and conclusions were the same.

Another limitation concerns our sample. Participants in this study did not stem from one organization but from many, which limits insights from specific events and procedures within one company. There are, however, also advantages, like the limited range restriction in our sample, as participants stem from multiple organizations and from various regions in the country, and that it started off as a representative sample (Frese \& Zapf, 1988). Our sample represents a wide range of occupations, which is a clear 
advantage in terms of generalizability of the results. This also means that the present results are not subject to singular shocks to the system, such as a change of the CEO in one company. In sum, our sample of Swedish workers adds to the landscape of research on justice and health. Furthermore, the hypotheses were tested with the rigorous statistical approach of a cross-lagged design (Little et al., 2007), which allows to study the direction of relationships taking autoregressive effects into consideration.

\section{Practical Implications}

In terms of practical implications, this study suggests that organizations should be aware of the relevance and importance of the fairness of the decision-making procedures at the workplace. Justice has an impact on health over time, as far as depressive symptoms and sickness absence are regarded. Individuals with depressive symptoms or those who withdraw and take sickness leave are costly for organizations. Many organizations today are concerned with increasing the health, mental and physical, level of their staff. This study suggests that fair treatment through transparent decision-making and organizational procedures is helpful to alleviate the direct and indirect costs related to health problems and sickness absence. The study results also indicate that procedural justice and mental preoccupation about work are related rather simultaneously, suggesting that fair treatment may reduce negative rumination about work outside of work. Despite the relationship with depressive symptoms, negative rumination about work is likely to have negative effects on work attitudes and behaviors. Therefore, it is beneficial for organizations to emphasize transparent decision-making and voice.

This research also provides clear indication that employees with past or present health problems, depressive symptoms, and higher amount of sickness absence over time perceive their organization as less fair when it comes to procedural justice. Organizations may need to give extra attention to these individuals, be it by monitoring their fairness perceptions, the way they are included in the workplace, or how their integration, their voice, and their insight into things that happen in the organization are guaranteed. Here, perhaps organizations need better routines for individuals with health problems or higher sickness absence rates. One important factor to pay attention to is the social side of work. Specifically, social support played an important role for the change in health but also for the change in justice perceptions. Therefore, our results emphasize that both supervisors and coworkers are relevant for creating a fair and healthy workplace. In sum, this study supports that fair treatment at work does have the "potential for improving the effectiveness of work organizations while simultaneously improving the lives of employees" (Cropanzano \& Ambrose, 2015, p. 13).

\section{Conclusions}

Many studies on organizational justice and health and wellbeing outcomes have been published, and some have even postulated justice as a new psychosocial predictor of health (Elovainio, Kivimäki, \& Vahtera, 2002). Occupational health psychology has been criticized for cross-sectional examinations between variables and for a lack of careful theoretical explanation of mechanisms for potential associations (Kompier \& Taris, 2011). This study uses a full panel design with three waves of data, based on a large-scale survey project. As previous studies have reported inconsistent findings regarding justice and health relationships, our study design contributes to the occupational health psychology literature by allowing more rigorous testing of "normal causation" and "reversed causation" longitudinal associations between justice perceptions and health. Results revealed general support for lagged effects between procedural justice perceptions to health, although not for all health indicators (self-rated health). Contrary, the different health indicators we studied consistently had a longitudinal relationship to procedural justice perceptions. In addition to these direct effects, this study examines indirect effects for the justicehealth and health-justice relationships. One previously suggested mediator, mental preoccupation with work, did not mediate the longitudinal relationship between procedural justice and different health outcomes. Although this result underlines the importance of replication studies, we offer explanations based on justice facets and immediate versus delayed mechanisms. This study highlights the limited knowledge of mechanisms for justice-health associations. Given the results showing justice is an independent predictor of health next to the famous demand-control-support model (Ndjaboué et al., 2012), this lack of knowledge on processes is particularly noteworthy. Different scholars situated in the work stress literature have suggested mechanisms behind potential "reversed" effects from health status to work stressor. This study adds to this discussion by testing one specific mechanism, social support. Results support that social support at work acts as a mediator for the longitudinal relationship between health-justice. A next step would be to further test whether this is due to a perception effect or whether health status also triggers real changes of the work environment. Moreover, this result provides an interesting avenue for justice scholars, as the intricate relationship between justice and social support has not received much attention so far. In sum, employers are well advised to consider fairness perceptions of employees. Similarly, employees' health status is particularly important to pay attention to by employers because of substantial effects on perceptions of the work environment.

\section{References}

Ambrose, M. L., \& Schminke, M. (2009). The role of overall justice judgments in organizational justice research: A test of mediation. Journal of Applied Psychology, 94, 491-500. http://dx.doi.org/10.1037/ a0013203

Barclay, L. J., \& Saldanha, M. (2016). Facilitating forgiveness in organizational contexts: Exploring the injustice gap, emotions, and expressive writing interventions. Journal of Business Ethics, 137, 699-720. http:// dx.doi.org/10.1007/s10551-015-2750-x

Barclay, L. J., \& Skarlicki, D. P. (2009). Healing the wounds of organizational injustice: Examining the benefits of expressive writing. Journal of Applied Psychology, 94, 511-523. http://dx.doi.org/10.1037/ a0013451

Barsky, A., \& Kaplan, S. A. (2007). If you feel bad, it's unfair: A quantitative synthesis of affect and organizational justice perceptions. Journal of Applied Psychology, 92, 286-295. http://dx.doi.org/10.1037/ 0021-9010.92.1.286

Black, D. C., \& Drost, D. (2011). Health at work-An independent review of sickness absence. London, United Kingdom: The Stationery Office Limited. 
Blader, S. L., \& Tyler, T. R. (2009). Testing and extending the group engagement model: Linkages between social identity, procedural justice, economic outcomes, and extrarole behavior. Journal of Applied Psychology, 94, 445-464. http://dx.doi.org/10.1037/a0013935

Brosschot, J. F., Gerin, W., \& Thayer, J. F. (2006). The perseverative cognition hypothesis: A review of worry, prolonged stress-related physiological activation, and health. Journal of Psychosomatic Research, 60, 113-124. http://dx.doi.org/10.1016/j.jpsychores.2005.06.074

Brosschot, J. F., Pieper, S., \& Thayer, J. F. (2005). Expanding stress theory: Prolonged activation and perseverative cognition. Psychoneuroendocrinology, 30, 1043-1049. http://dx.doi.org/10.1016/j.psyneuen .2005.04.008

Caverley, N., Cunningham, J. B., \& MacGregor, J. N. (2007). Sickness presenteeism, sickness absenteeism, and health following restructuring in a public service organization. Journal of Management Studies, 44, 304-319. http://dx.doi.org/10.1111/j.1467-6486.2007.00690.x

Cole, D. A., \& Maxwell, S. E. (2003). Testing mediational models with longitudinal data: Questions and tips in the use of structural equation modeling. Journal of Abnormal Psychology, 112, 558-577. http://dx.doi .org/10.1037/0021-843X.112.4.558

Colquitt, J. A. (2001). On the dimensionality of organizational justice: A construct validation of a measure. Journal of Applied Psychology, 86, 386-400. http://dx.doi.org/10.1037/0021-9010.86.3.386

Colquitt, J. A., Conlon, D. E., Wesson, M. J., Porter, C. O. L. H., \& Ng, K. Y. (2001). Justice at the millennium: A meta-analytic review of 25 years of organizational justice research. Journal of Applied Psychology, 86, 425-445. http://dx.doi.org/10.1037/0021-9010.86.3.425

Colquitt, J. A., Scott, B. A., Rodell, J. B., Long, D. M., Zapata, C. P., Conlon, D. E., \& Wesson, M. J. (2013). Justice at the millennium, a decade later: A meta-analytic test of social exchange and affect-based perspectives. Journal of Applied Psychology, 98, 199-236. http://dx.doi .org/10.1037/a0031757

Cropanzano, R., \& Ambrose, M. L. (2015). The oxford handbook of justice in the workplace. New York, NY: Oxford University Press. http://dx.doi .org/10.1093/oxfordhb/9780199981410.001.0001

Cropanzano, R., Byrne, Z. S., Bobocel, D. R., \& Rupp, D. E. (2001). Moral virtues, fairness heuristics, social entities, and other denizens of organizational justice. Journal of Vocational Behavior, 58, 164-209. http://dx .doi.org/10.1006/jvbe.2001.1791

Daniels, K., \& Guppy, A. (1997). Stressors, locus of control, and social support as consequences of affective psychological well-being. Journal of Occupational Health Psychology, 2, 156-174. http://dx.doi.org/10 .1037/1076-8998.2.2.156

De Boer, E. M., Bakker, A. B., Syroit, J. E., \& Schaufeli, W. B. (2002). Unfairness at work as a predictor of absenteeism. Journal of Organizational Behavior, 23, 181-197. http://dx.doi.org/10.1002/job.135

de Lange, A. H., Taris, T. W., Kompier, M. A. J., Houtman, I. L. D., \& Bongers, P. M. (2004). The relationships between work characteristics and mental health: Examining normal, reversed and reciprocal relationships in a 4-wave study. Work and Stress, 18, 149-166. http://dx.doi .org/10.1080/02678370412331270860

de Lange, A. H., Taris, T. W., Kompier, M. A., Houtman, I. L., \& Bongers, P. M. (2005). Different mechanisms to explain the reversed effects of mental health on work characteristics. Scandinavian Journal of Work, Environment and Health, 31, 3-14. http://dx.doi.org/10.5271/sjweh.843

Dormann, C., \& Griffin, M. A. (2015). Optimal time lags in panel studies. Psychological Methods, 20, 489-505. http://dx.doi.org/10.1037/ met0000041

Eib, C., von Thiele Schwarz, U., \& Blom, V. (2015). Don't let it get to you! A moderated mediated approach to the (in)justice-health relationship. Journal of Occupational Health Psychology, 20, 434-445. http://dx.doi .org/10.1037/a0039005

Elovainio, M., Ferrie, J. E., Gimeno, D., De Vogli, R., Shipley, M., Brunner, E. J., . . Kivimäki, M. (2009). Organizational justice and sleeping problems: The Whitehall II study. Psychosomatic Medicine, 71, 334-340. http://dx.doi.org/10.1097/PSY.0b013e3181960665

Elovainio, M., Heponiemi, T., Jokela, M., Hakulinen, C., Presseau, J., Aalto, A.-M., \& Kivimäki, M. (2015). Stressful work environment and wellbeing: What comes first? Journal of Occupational Health Psychology, 20, 289-300. http://dx.doi.org/10.1037/a0038684

Elovainio, M., Kivimäki, M., \& Vahtera, J. (2002). Organizational justice: Evidence of a new psychosocial predictor of health. American Journal of Public Health, 92, 105-108. http://dx.doi.org/10.2105/AJPH.92.1.105

Elovainio, M., Kivimäki, M., Vahtera, J., Keltikangas-Järvinen, L., \& Virtanen, M. (2003). Sleeping problems and health behaviors as mediators between organizational justice and health. Health Psychology, 22, 287-293. http://dx.doi.org/10.1037/0278-6133.22.3.287

Elovainio, M., Linna, A., Virtanen, M., Oksanen, T., Kivimäki, M., Pentti, J., \& Vahtera, J. (2013). Perceived organizational justice as a predictor of long-term sickness absence due to diagnosed mental disorders: Results from the prospective longitudinal Finnish Public Sector Study. Social Science and Medicine, 91, 39-47. http://dx.doi.org/10.1016/j socscimed.2013.05.008

Elovainio, M., van den Bos, K., Linna, A., Kivimäki, M., Ala-Mursula, L., Pentti, J., \& Vahtera, J. (2005). Combined effects of uncertainty and organizational justice on employee health: Testing the uncertainty management model of fairness judgments among Finnish public sector employees. Social Science and Medicine, 61, 2501-2512. http://dx.doi .org/10.1016/j.socscimed.2005.04.046

Enders, C. K., \& Bandalos, D. L. (2001). The relative performance of full information maximum likelihood estimation for missing data in structural equation models. Structural Equation Modeling, 8, 430-457. http://dx.doi.org/10.1207/S15328007SEM0803_5

Firth-Cozens, J., \& Hardy, G. E. (1992). Occupational stress, clinical treatment and changes in job perceptions. Journal of Occupational and Organizational Psychology, 65, 81-88. http://dx.doi.org/10.1111/j 2044-8325.1992.tb00486.x

Fortin, M., Cojuharenco, I., Patient, D., \& German, H. (2016). It is time for justice: How time changes what we know about justice judgments and justice effects. Journal of Organizational Behavior, 37, S30-S56. http:// dx.doi.org/10.1002/job.1958

Fredriksson, K., Toomingas, A., Torgén, M., Thorbjörnsson, C. B., \& Kilbom, A. (1998). Validity and reliability of self-reported retrospectively collected data on sick leave related to musculoskeletal diseases. Scandinavian Journal of Work, Environment and Health, 24, 425-431.

Frese, M., \& Zapf, D. (1988). Methodological issues in the study of work stress: Objective vs subjective measurement of work stress and the question of longitudinal studies. In C. L. Cooper \& R. L. Payne (Eds.), Causes, coping and consequences of stress at work, (pp. 375-387). New York, NY: Wiley.

Fujishiro, K., \& Heaney, C. A. (2009). Justice at work, job stress, and employee health. Health Education and Behavior, 36, 487-504. http:/ dx.doi.org/10.1177/1090198107306435

Ganster, D. C., \& Rosen, C. C. (2013). Work stress and employee health: A multidisciplinary review. Journal of Management, 39, 1085-1122. http://dx.doi.org/10.1177/0149206313475815

Ganzel, B. L., Morris, P. A., \& Wethington, E. (2010). Allostasis and the human brain: Integrating models of stress from the social and life sciences. Psychological Review, 117, 134-174. http://dx.doi.org/10 .1037/a0017773

Greenberg, J. (2004). Stress fairness to fare no stress: Managing workplace stress by promoting organizational justice. Organizational Dynamics, 33, 352-365. http://dx.doi.org/10.1016/j.orgdyn.2004.09.003

Greenberg, J. (2010). Organizational injustice as an occupational health risk. The Academy of Management Annals, 4, 205-243. http://dx.doi.org/ 10.1080/19416520.2010.481174

Hayduk, L. A. (1987). Structural equation modeling with LISREL: Essentials and advances. Baltimore, MD: Johns Hopkins University Press. 
Howard, L. W., \& Cordes, C. L. (2010). Flight from unfairness: Effects of perceived injustice on emotional exhaustion and employee withdrawal. Journal of Business and Psychology, 25, 409-428. http://dx.doi.org/10 .1007/s10869-010-9158-5

Hu, L.-T., \& Bentler, P. M. (1995). Evaluating model fit. In R. H. Hoyle (Ed.), Structural equation modeling: Concepts, issues, and applications (pp. 76-99). Thousand Oaks, CA: Sage.

Ibrahim, S., Smith, P., \& Muntaner, C. (2009). A multi-group cross-lagged analyses of work stressors and health using Canadian National sample. Social Science and Medicine, 68, 49-59. http://dx.doi.org/10.1016/j .socscimed.2008.10.019

Idler, E. L., \& Benyamini, Y. (1997). Self-rated health and mortality: A review of twenty-seven community studies. Journal of Health and Social Behavior, 38, 21-37. http://dx.doi.org/10.2307/2955359

Judge, T. A., \& Colquitt, J. A. (2004). Organizational justice and stress: The mediating role of work-family conflict. Journal of Applied Psychology, 89, 395-404. http://dx.doi.org/10.1037/0021-9010.89.3.395

Juster, R.-P., Marin, M.-F., Sindi, S., Nair, N. P. V., Ng, Y. K., Pruessner, J. C., \& Lupien, S. J. (2011). Allostatic load associations to acute, 3-year and 6-year prospective depressive symptoms in healthy older adults. Physiology and Behavior, 104, 360-364. http://dx.doi.org/10.1016/j .physbeh.2011.02.027

Kalimo, R., Taris, T. W., \& Schaufeli, W. B. (2003). The effects of past and anticipated future downsizing on survivor well-being: An equity perspective. Journal of Occupational Health Psychology, 8, 91-109. http://dx.doi.org/10.1037/1076-8998.8.2.91

Kawachi, I. (2006). Injustice at work and health: Causation or correlation? Occupational and Environmental Medicine, 63, 578-579. http://dx.doi .org/10.1136/oem.2006.028365

Kivimäki, M., Elovainio, M., Vahtera, J., \& Ferrie, J. E. (2003). Organisational justice and health of employees: Prospective cohort study Occupational and Environmental Medicine, 60, 27-34. http://dx.doi.org/ 10.1136/oem.60.1.27

Kompier, M. A. J., \& Taris, T. W. (2011). Understanding the causal relations between psychosocial factors at work and health-A circular process. Scandinavian Journal of Work, Environment and Health, 37 259-262. http://dx.doi.org/10.5271/sjweh.3172

Lang, J., Bliese, P. D., Lang, J. W. B., \& Adler, A. B. (2011). Work gets unfair for the depressed: Cross-lagged relations between organizational justice perceptions and depressive symptoms. Journal of Applied Psychology, 96, 602-618. http://dx.doi.org/10.1037/a0022463

Lind, E. A. (2001). Fairness heuristic theory: Justice judgments as pivotal cognitions in organizational relations. In J. Greenberg \& R. Cropanzano (Eds.), Advances in organizational justice (pp. 56-88). Stanford, CA: Stanford University Press.

Little, T. D., Preacher, K. J., Selig, J. P., \& Card, N. A. (2007). New developments in latent variable panel analyses of longitudinal data. International Journal of Behavioral Development, 31, 357-365. http:// dx.doi.org/10.1177/0165025407077757

Magnusson Hanson, L. L., Chungkham, H. S., Åkerstedt, T., \& Westerlund, H. (2014). The role of sleep disturbances in the longitudinal relationship between psychosocial working conditions, measured by work demands and support, and depression. Sleep, 37, 1977-1985. http://dx.doi.org/10.5665/sleep.4254

Magnusson Hanson, L. L., Westerlund, H., Leineweber, C., Rugulies, R., Osika, W., Theorell, T., \& Bech, P. (2014). The Symptom Checklistcore depression (SCL-CD6) scale: Psychometric properties of a brief six item scale for the assessment of depression. Scandinavian Journal of Public Health, 42, 82-88. http://dx.doi.org/10.1177/1403494813500591

Manville, C., Akremi, A. E., Niezborala, M., \& Mignonac, K. (2016). Injustice hurts, literally: The role of sleep and emotional exhaustion in the relationship between organizational justice and musculoskeletal disorders. Human Relations, 69, 1315-1339. http://dx.doi.org/10.1177/ 0018726715615927
McEwen, B. S. (2000). Allostasis and allostatic load: Implications for neuropsychopharmacology. Neuropsychopharmacology, 22, 108-124. http://dx.doi.org/10.1016/S0893-133X(99)00129-3

McEwen, B. S. (2008). Central effects of stress hormones in health and disease: Understanding the protective and damaging effects of stress and stress mediators. European Journal of Pharmacology, 583, 174-185. http://dx.doi.org/10.1016/j.ejphar.2007.11.071

Melamed, S., Armon, G., Shirom, A., \& Shapira, I. (2011). Exploring the reciprocal causal relationship between job strain and burnout: A longitudinal study of apparently healthy employed persons. Stress and Health: Journal of the International Society for the Investigation of Stress, 27, 272-281. http://dx.doi.org/10.1002/smi.1356

Moorman, R. H. (1991). Relationship between organizational justice and organizational citizenship behaviors: Do fairness perceptions influence employee citizenship? Journal of Applied Psychology, 76, 845-855. http://dx.doi.org/10.1037/0021-9010.76.6.845

Ndjaboué, R., Brisson, C., \& Vézina, M. (2012). Organisational justice and mental health: A systematic review of prospective studies. Occupational and Environmental Medicine, 69, 694-700. http://dx.doi.org/10.1136/ oemed-2011-100595

Querstret, D., \& Cropley, M. (2012). Exploring the relationship between work-related rumination, sleep quality, and work-related fatigue. Journal of Occupational Health Psychology, 17, 341-353. http://dx.doi.org/ 10.1037/a0028552

Robbins, J. M., Ford, M. T., \& Tetrick, L. E. (2012). Perceived unfairness and employee health: A meta-analytic integration. Journal of Applied Psychology, 97, 235-272. http://dx.doi.org/10.1037/a0025408

Roe, R. A. (2008). Time in applied psychology: The study of "what happens" rather than "what is". European Psychologist, 13, 37-52. http://dx.doi.org/10.1027/1016-9040.13.1.37

Rousseau, V., Salek, S., Aubé, C., \& Morin, E. M. (2009). Distributive justice, procedural justice, and psychological distress: The moderating effect of coworker support and work autonomy. Journal of Occupational Health Psychology, 14, 305-317. http://dx.doi.org/10.1037/a0015747

Rupp, D. E., \& Cropanzano, R. (2002). The mediating effects of social exchange relationships in predicting workplace outcomes from multifoci organizational justice. Organizational Behavior and Human Decision Processes, 89, 925-946. http://dx.doi.org/10.1016/S0749-5978(02)00036-5

Rupp, D. E., Shao, R., Jones, K. S., \& Liao, H. (2014). The utility of a multifoci approach to the study of organizational justice: A metaanalytic investigation into the consideration of normative rules, moral accountability, bandwidth-fidelity, and social exchange. Organizational Behavior and Human Decision Processes, 123, 159-185. http://dx.doi .org/10.1016/j.obhdp.2013.10.011

Siegrist, J., Starke, D., Chandola, T., Godin, I., Marmot, M., Niedhammer, I., \& Peter, R. (2004). The measurement of effort-reward imbalance at work: European comparisons. Social Science and Medicine, 58, 14831499. http://dx.doi.org/10.1016/S0277-9536(03)00351-4

Sonnentag, S. (2012). Psychological detachment from work during leisure time: The benefits of mentally disengaging from work. Current Directions in Psychological Science, 21, 114-118. http://dx.doi.org/10.1177/ 0963721411434979

Spector, P. E., Zapf, D., Chen, P. Y., \& Frese, M. (2000). Why negative affectivity should not be controlled in job stress research: Don't throw out the baby with the bath water. Journal of Organizational Behavior, 21, 79-95. http://dx.doi.org/10.1002/(SICI)1099-1379(200002)21: $1<79:$ :AID-JOB964>3.0.CO;2-G

Spell, C. S., \& Arnold, T. (2007). An appraisal perspective of justice, structure, and job control as antecedents of psychological distress. Journal of Organizational Behavior, 28, 729-751. http://dx.doi.org/10.1002/ job.441

Sundelin, T., Karshikoff, B., Axelsson, E., Höglund, C. O., Lekander, M., \& Axelsson, J. (2015). Sick man walking: Perception of health status 
from body motion. Brain, Behavior, and Immunity, 48, 53-56. http://dx .doi.org/10.1016/j.bbi.2015.03.007

Tang, K. (2014). A reciprocal interplay between psychosocial job stressors and worker well-being? A systematic review of the "reversed" effect. Scandinavian Journal of Work, Environment and Health, 40, 441-456. http://dx.doi.org/10.5271/sjweh.3431

Tepper, B. J. (2001). Health consequences of organizational injustice: Tests of main and interactive effects. Organizational Behavior and Human Decision Processes, 86, 197-215. http://dx.doi.org/10.1006/ obhd.2001.2951

Theorell, T., Perski, A., Åkerstedt, T., Sigala, F., Ahlberg-Hultén, G., Svensson, J., \& Eneroth, P. (1988). Changes in job strain in relation to changes in physiological state. A longitudinal study. Scandinavian Journal of Work, Environment and Health, 14, 189-196. http://dx.doi.org/ 10.5271/sjweh.1932

Thibaut, J., \& Walker, L. (1975). Procedural justice: A psychological analysis. Hillsdale, NJ: Erlbaum.

Tyler, T. R., \& Blader, S. L. (2003). The group engagement model: Procedural justice, social identity, and cooperative behavior. Personality and Social Psychology Review, 7, 349-361. http://dx.doi.org/10.1207/ S15327957PSPR0704_07

Vandenberg, R. J., \& Lance, C. E. (2000). A review and synthesis of the measurement invariance literature: Suggestions, practices, and recommendations for organizational research. Organizational Research Methods, 3, 4-70. http://dx.doi.org/10.1177/109442810031002 van den Bos, K. (2003). On the subjective quality of social justice: The role of affect as information in the psychology of justice judgments. Journal of Personality and Social Psychology, 85, 482-498. http://dx.doi.org/10 $.1037 / 0022-3514.85 .3 .482$

van Prooijen, J.-W. (2009). Procedural justice as autonomy regulation. Journal of Personality and Social Psychology, 96, 1166-1180. http:// dx.doi.org/10.1037/a0014153

Vermunt, R., \& Steensma, H. (2001). Stress and justice in organizations: An exploration into justice processes with the aim to find mechanisms to reduce stress. In R. Cropanzano (Ed.), Justice in the workplace: From theory to practice (Vol. 2, pp. 27-48). Mahwah, NJ: Erlbaum.

Wanous, J. P., Reichers, A. E., \& Hudy, M. J. (1997). Overall job satisfaction: How good are single-item measures? Journal of Applied Psychology, 82, 247-252. http://dx.doi.org/10.1037/0021-9010.82.2.247

Ybema, J. F., \& van den Bos, K. (2010). Effects of organizational justice on depressive symptoms and sickness absence: A longitudinal perspective. Social Science and Medicine, 70, 1609-1617. http://dx.doi.org/10 .1016/j.socscimed.2010.01.027

Zapf, D., Dormann, C., \& Frese, M. (1996). Longitudinal studies in organizational stress research: A review of the literature with reference to methodological issues. Journal of Occupational Health Psychology, 1, 145-169. http://dx.doi.org/10.1037/1076-8998.1.2.145

Received June 13, 2016

Revision received January 20, 2018

Accepted January 25, 2018 


\section{AUTHOR QUERIES}

\section{AUTHOR PLEASE ANSWER ALL QUERIES}

AQau-Please confirm the given-names and surnames are identified properly by the colors. = Given-Name, $\boldsymbol{a}=$ Surname The colors are for proofing purposes only. The colors will not appear online or in print.

AQ1-Author: Please be sure to provide the name of the department(s) with which you and your coauthors are affiliated at your respective institutes if you have not already done so. If you are affiliated with a governmental department, business, hospital, clinic, VA center, or other nonuniversity-based institute, please provide the city and U.S. state (or the city, province, and country) in which the institute is based. Departments should be listed in the author footnote only, not the byline. If you or your coauthors have changed affiliations since the article was written, please include a separate note indicating the new department/affiliation: [author's name] is now at [affiliation].

AQ4-Author: Please confirm if the edit in the sentence "Moreover, unhealthy individuals may underperform and receive..." conveys your intended meaning.

AQ5-Author: Please cite "** in the body of Table 1.

AQ6-Author: Please include a heading for col. 1 of Tables 2, 3 and 4.

AQ7-Author: “*** is not cited in the table body. Please do so; alternatively, delete the footnote. Also, please provide spelled-out form for OVC in Tables 3 and 4.

AQ8-Author: Please confirm use of gender vs. sex throughout (according to the APA, sex usually refers to the biological aspects of maleness or femaleness, whereas gender implies the psychological, behavioral, social, and cultural aspects of being male or female [i.e., masculinity or femininity.]) 